1994-03-01

\title{
Vegetation studies of the Amazon basin using enhanced resolution Seasat scatterometer data
}

David G. Long

david_long@byu.edu

Perry J. Hardin

perry_hardin@byu.edu

Peter T. Whiting

Follow this and additional works at: https://scholarsarchive.byu.edu/facpub

Part of the Electrical and Computer Engineering Commons

\section{Original Publication Citation}

Long, D. G., and P. J. Hardin. "Vegetation Studies of the Amazon Basin using Enhanced Resolution Seasat Scatterometer Data." Geoscience and Remote Sensing, IEEE Transactions on 32.2 (1994): 449-6

\section{BYU ScholarsArchive Citation}

Long, David G.; Hardin, Perry J.; and Whiting, Peter T., "Vegetation studies of the Amazon basin using enhanced resolution Seasat scatterometer data" (1994). Faculty Publications. 702.

https://scholarsarchive.byu.edu/facpub/702 


\title{
Vegetation Studies of the Amazon Basin Using Enhanced Resolution Seasat Scatterometer Data
}

\author{
David G. Long and Perry J. Hardin
}

\begin{abstract}
The Seasat-A scatterometer (SASS) was designed to measure the near-surface wind field over the ocean by inferring the wind from measurements of the surface radar backscatter. While backscatter measurements were also made over land, they have been primarily used for the calibration of the instrument. This has been due in part to the low resolution of the scatterometer measurements (nominally $50 \mathrm{~km}$ ). In a separate paper [7], we introduced a new method for generating enhanced resolution radar measurements of the earth's surface using spaceborne scatterometry. In this paper, the method is used with SASS data to study vegetation classification over the extended Amazon basin using the resulting medium-scale radar images. The remarkable correlation between the $K u$-band radar images and vegetation formations is explored, and the results of several successful experiments to classify the general vegetation classes using the image data are presented. The results demonstrate the utility of medium-scale radar imagery in the study of tropical vegetation and permit utilization of both historic and contemporary scatterometer data for studies of global change. Because the scatterometer provides frequent, wide-area coverage at a variety of incidence angles, it can supplement higher resolution instruments which often have narrow swaths with limited coverage and incidence angle diversity.
\end{abstract}

\section{INTRODUCTION}

QPACEBORNE wind scatterometers are an important Delement in future remote sensing systems because of their proven ability to make all-weather measurements of vector winds over the ocean, a capability first demonstrated by the $K u$-band $(14.6 \mathrm{GHz})$ Seasat scatterometer (SASS) in 1978 [14]. Scatterometers measure the normalized radar backscatter coefficient $\left(\sigma^{\circ}\right)$ of the earth's surface. Over the ocean, the $\sigma^{\circ}$ measurements can be used to estimate the near-surface wind [14].

The coarse resolution (nominally $50 \mathrm{~km}$ ) of the scatterometer measurements, while suitable for ocean wind measurement, is a significant limitation in the application of scatterometer data to land and ice studies. The principle application of land $\sigma^{\circ}$ measurements has been in the calibration of the scatterometer using tropical forests as homogeneous targets [3], [10]. However, global studies

Manuscript received April 8, 1992; revised October 22, 1992 and February 9,1993 . This work was supported by the NASA HQ Physical Oceanography and Polar Sciences Programs.

The authors are with the Department of Electrical and Computer Engineering, Brigham Young University, Provo, UT 84602

IEEE Log Number 9214662 (e.g., [4], [5], [13]) have indicated that the $\sigma^{\circ}$ measurements are very sensitive to vegetation and physiographic type, and may provide valuable information for discriminating between land cover classes.

In a separate paper [7] (hereafter LHW), we introduced a new method for obtaining enhanced resolution radar images from low-resolution scatterometer measurements. In this paper, we use the method to generate enhanced resolution images of the extended Amazon basin. Using these medium-scale SASS-derived images, a series of experiments in vegetation classification were conducted. We conclude that the medium-scale enhanced resolution images can be very useful in studies of tropical vegetation.

This paper is organized as follows. We first briefly provide some background in scatterometry theory, a description of the SASS data used, and an overview of our enhanced resolution imaging technique. (A detailed description of the enhanced resolution imaging technique is presented in LHW.) Data considerations and assumptions required to apply the technique to SASS data are then discussed. We present enhanced resolution radar images of the extended Amazon basin generated from the SASS data, and then provide the results of several vegetation classification experiments based on the images. We consider both vertically and horizontally polarized measurements. Finally, we summarize our results.

\section{BACKGROUND}

Wind scatterometers such as SASS observe $\sigma^{\circ}$ over a wide range of incidence angles, at several azimuth angles, and with both horizontal and vertical polarizations. The SASS measurement cells had nominally $50 \mathrm{~km}$ resolution on an irregular $50 \mathrm{~km}$ grid; however, they varied in size and shape across the measurement swath and along the orbit track (see Fig. 1). Further details regarding the SASS measurement method and the measurement geometry are contained in LHW.

For the purposes of applying our resolution enhancement method, we have adopted a simple model describing the dependence of $\sigma^{\circ}$ on the incidence angle $\theta$, i.e. [4],

$$
10 \log _{10} \sigma^{\circ}(\theta)=Q+Q B\left(\theta-40^{\circ}\right)
$$




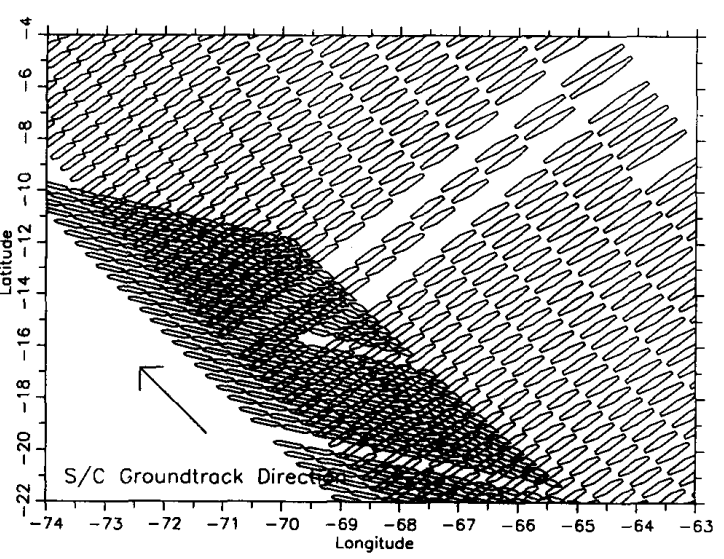

Fig. 1. An illustration of the ranges of sizes and shapes of the SASS $\sigma^{\circ}$ cells used in generating the images in this paper. Only $\sigma^{\circ}$ cells with incidence angles in the range of $23^{\circ} \leq \theta \leq 55^{\circ}$ are shown. While SASS also made nadir $\sigma^{\circ}$ measurements, these are not used in this paper.

where $\theta$ is the incidence angle of the observation and $Q$ and $B$ are constants dependent only on the observed surface characteristics. For the experiments described below, this method is applied only over the relatively narrow incidence angle range of $23^{\circ}<\theta<57^{\circ}$. Bracalente and Sweet determined this linear model to be accurate with $0.5 \mathrm{~dB}$ over this range. In this model, $Q$ is the value of $\sigma^{\circ}$ at an incidence angle of $40^{\circ}$. $Q$ can thus be considered to be the "incidence angle-normalized" $\sigma^{\circ}$. Because of the diversity of measurement incidence angles used by wind scatterometers, the $Q$ and $B$ coefficients of this model are more useful in application than the direct $\sigma^{\circ}$ measurements [5], [6].

Data from the first spaceborne scatterometer, the Skylab S-193 experiment, showed that the $14.6 \mathrm{GHz} \sigma^{\circ}$ values over land were sensitive to vegetation cover, surface water, soil moisture, and physiography [13]. Because the Amazon rain forest appeared to be homogeneous, azimuthally isotropic, and relatively insensitive to polarization with a small diurnal variation, $\sigma^{\circ}$ measurements of the Amazon rain forest were used for calibration of SASS [1], [3], [4], [10]. Later, Kennett and Li [5], [6] conducted a study of SASS measurements over land at a resolution of $1 \times 1^{\circ}$ in a search for additional homogeneous areas for future scatterometer instrument calibration. They found remarkable correlation between land cover types and the values of $Q$ and $B$ with $0.1 \leq B \leq 0.22 \mathrm{~dB} /{ }^{\circ}$ and $-40 \leq a \leq 0 \mathrm{~dB}$, depending on the surface type and vegetation cover. While the early demise of Seasat precluded study of the seasonal change of the backscatter versus land type, they found significant variability in the Arctic region and other areas undergoing high seasonal change during the abbreviated three-month mission (JulySeptember 1978). However, the Amazon and Congo rain forests and various desert regions (mapped at a somewhat higher resolution of $0.5 \times 0.5^{\circ}$ ) proved to be remarkably stable, and were thus deemed suitable targets for future scatterometer calibration activities.

\section{The SASS DATA}

The SASS Sensor Data Record (SDR) files used in this study are described in [2]. While the SASS SDR files do not include the integrated cell corners, we developed an algorithm for reconstructing the cell corner positions from data available in the SDR files (see Fig. 1). The SDR files contain $\sigma^{\circ}$ measurements spanning an incidence angle range of $0-70^{\circ}$ and include estimates of the normalized standard deviation $\left(K_{p}\right)$ for each $\sigma^{\circ}$ measurement. We have chosen to exclude $\sigma^{\circ}$ measurements with excessive $K_{p}\left(K_{p}>15 \%\right)$ in the experiments described below. The discarded measurements represent fewer than $5 \%$ of the measurements, most of which occurred at large incidence angles. Orbits (revs) for which the measurements exhibited excessive error were not included (see [4] for a detailed description of the SASS data anomalies and the rationale for selecting and excluding orbits with excessive error).

To illustrate the variability in the scatterometer data as well as demonstrate the validity of the model, all the vertically polarized $\sigma^{\circ}$ measurements over the three-month mission from a $4 \times 4^{\circ}$ region in northeastern Brazil were plotted as a function of the measurement incidence angle (see Fig. 2). Only measurements with incidence angles in the range of $23-57^{\circ}$ with $K_{p}<15 \%$ were used. This region is a portion of the Amazon tropical rain forest, an area previously noted for its homogeneous radar response. Linear regression was used to compute the $Q$ and $\mathbb{B}$ coefficients and the corresponding line shown. As evident from this figure, the linear model fits the data well, although there is significant data scatter about the best-fit line. This scatter is due to: 1) thermal noise in the instrument, 2) errors in the computation of the radar parameters used to compute $\sigma^{\circ}$ from the measured power (this is known as "retrieval error"), 3) variations in the radar backscatter of the forest canopy, and 4) variations in the calibration of the SASS instrument. The latter effect probably accounts for less than $0.1 \mathrm{~dB}$ [4]. The additive error due to the retrieval error and the thermal noise are both subsumed into $K_{p}$ (see LHW), although for the ranges of $\sigma^{\circ}$ observed over land, $K_{p}$ is dominated by the retrieval error. The standard deviation of the canopy backscatter is estimated to be $0.15 \mathrm{~dB}$ [4].

The temporal variation in the radar response can be observed with the aid of Fig. 3 which contains plots of the vertically polarized $Q$ and $B$ versus Julian day (1978) for the study region defined above. The same measurements used in Fig. 2 were employed in creating these plots. To generate this plot, a moving ten-day window was used to compute a time-averaged $Q$ and $B$ value by linear regression of the $\sigma^{\circ}$ versus incidence angle within the temporal window. The corresponding time-averaged $Q$ and $Q$ coefficients were plotted as lines in the upper portion of the plot. To illustrate the frequent changes in the measurements as a function of time, the time-averaged $B$ value from the upper plot was used to remove the incidence angle dependence of each $\sigma^{\circ}$ measurement. The resulting $\propto$ 


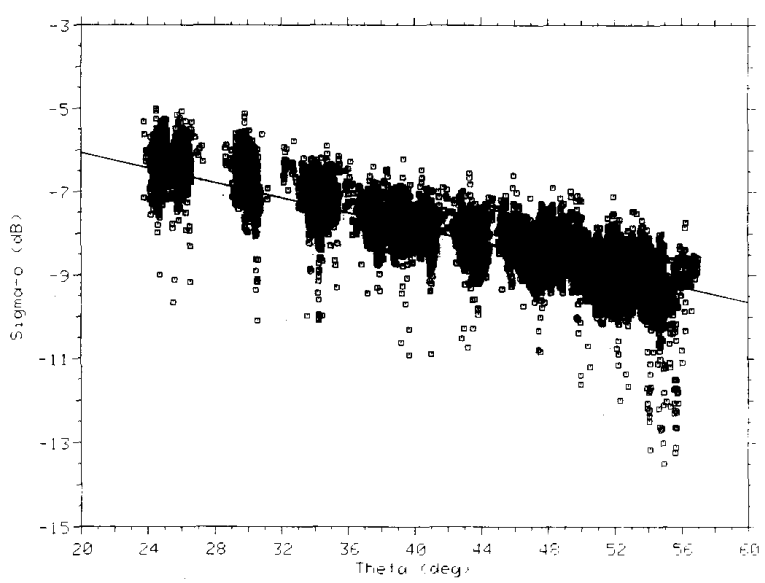

Fig. 2. A plot showing $\sigma^{\circ}$ (in $\mathrm{dB}$ ) versus incidence angle $\theta$ for vertically polarized $\sigma^{\circ}$ measurements from a $4 \times 4^{\circ}$ study region in northwest Brazil. The linear regression line $(Q=7.85, Q B=-0.894)$ is shown. The study region is centered at $45.5^{\circ} \mathrm{W}, 12^{\circ} \mathrm{N}$. Only $\sigma^{\circ}$ measurements with $K_{p}<$ $15 \%$ and $23^{\circ} \leq \theta \leq 55^{\circ}$ are plotted.

\section{Time Series of $\sigma^{\circ}$ values}

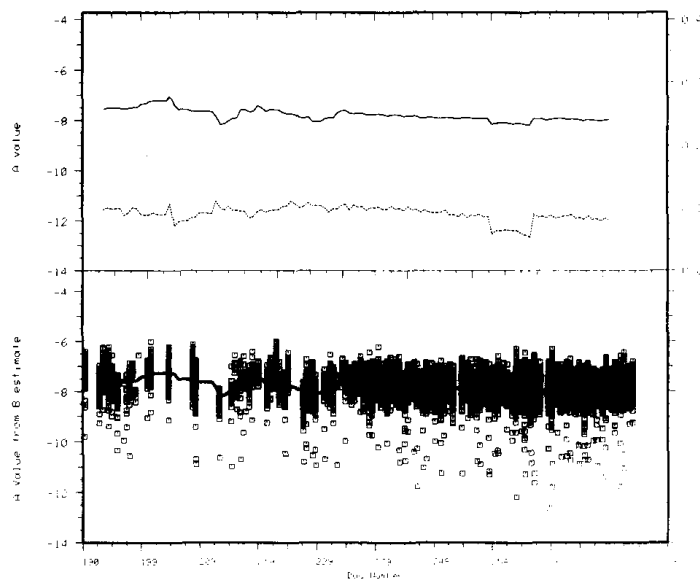

Fig. 3. Plots of vertically polarized $Q$ and $B$ determined from the measurements shown in Fig. 2. In the upper portion of this plot, the $\mathbb{Q}$ and $Q$ coefficients of the linear model using linear regression of $\sigma^{\circ}$ versus $\theta$ were computed for a ten-day window centered at the plotted point. The window was shifted one day and $Q$ and $Q$ recomputed using only the $\sigma^{\circ}$ measurements in the window. The lower plot was generated using the $B$ estimate from the upper plot to incidence angle "correct" the individual $\sigma{ }^{\circ}$ measurements. The corrected measurements ( $Q$ values) are plotted as square symbols. The heavy line in the lower plot is a plot of the average "corrected" value computed using a sliding 10-day window.

estimate was then plotted in the lower portion of Fig. 3 as individual symbols. A windowed time average of these points was plotted as a solid line on this plot. Gaps in the time series are due to missing data. We note that both $Q$ and $B$ remain relatively constant throughout the mission for this region of tropical forest. As discussed later, some seasonal variation in savanna areas was noted. In effect, the scatter in the $Q$ estimates in the lower plot is treated as measurement noise by the resolution enhancement algorithm.

\section{Enhanced Resolution Scatterometer Imaging}

In generating their regional maps, Kennett and $\mathrm{Li}$ used a "binning" technique for mapping $Q$ and $B$. In this technique, the study area was divided into rectangular "bins" ( $1^{\circ}$ or $0.5^{\circ}$ on a side). Each $\sigma^{\circ}$ measurement was assigned to the bin in which the cell center fell. $Q$ and $B$ were estimated for each bin using linear regression. The "binning" technique must use resolution "bins", no smaller than the largest measurement cell, limiting the resolution to no better than $50 \mathrm{~km}$.

Unfortunately, the $50 \mathrm{~km}$ intrinsic resolution of the scatterometer is too coarse for many studies. To ameliorate this problem, we developed a new technique for generating enhanced resolution images of $Q$ and $B$ from the low-resolution scatterometer measurements of $\sigma^{\circ}$. Our technique is based primarily on ground-based signal processing. The method takes advantage of the areal overlap in the backscatter measurements taken at different times of a given region and, using an indirect measurement (i.e., reconstruction) formulation, extends the effective resolution. However, the improved resolution is not without cost: the noise in the images of $Q$ and $B$ increases as we attempt to improve the resolution. Hence, a tradeoff must be made between resolution and the noise level. In addition, certain conditions on the data are required and various assumptions must be made. These will be described below.

Because of the spatial sampling characteristics of the SASS measurements, we must use data from multiple orbits to obtain sufficient measurement overlap to apply our reconstruction technique. ${ }^{1}$ To accurately estimate $\mathbb{Q}$ and $B$, we must assume that the target does not change appreciably during the imaging time interval. We define the "imaging time interval" as the length of time required to accumulate all the measurements used to reconstruct an enhanced resolution image.

The ultimate obtainable resolution with our technique is a function of the measurement cell overlap and the noise in the measurements. Arbitrarily reducing the size of the resolution elements will not increase the effective resolution of the resulting estimate since, as the resolution element size is decreased, the noise in the estimates increases. To minimize the estimate noise for a given resolution element size, the number of measurement cells should be maximized. In turn, however, increasing the number of measurements requires increasing the imaging time interval. Thus, the resolution element size must be a tradeoff between the imaging time interval and the image estimate noise level.

Our imaging technique provides estimates of $Q$ and $B$ for each element of a rectilinear grid of small resolution

'As discussed in LHW, for future scatterometers, this requirement may be relaxed. 
elements from the lower resolution $\sigma^{\circ}$ measurements. In this paper, the iterative SIRF (scatterometer image reconstruction with filtering at each stage) algorithm was used to generate enhanced resolution images of $Q$ and $B$ over the Amazon region of South America from three months of SASS data. For the images shown in this paper, the resolution element (pixel) size is $1 / 26 \times 1 / 26^{\circ}$ (approximately $4.2 \times 4.2 \mathrm{~km}$ ). When applied to SASS, this represents about the best resolution enhancement possible. As described in LHW, modifications to future scatterometers could result in an enhanced resolution of 1-2 km. These resolutions are similar to the resolution of local area coverage (LAC) from the Advanced Visible High Resolution Radiometer.

Although the enhanced images are only medium scale, our results demonstrate that they can be successfully applied to studies of tropical vegetation. Thus, this technique can be used to augment the data from existing and planned instruments, leading to their more effective use. The wider coverage of the enhanced scatterometer data may be more effective for large-scale monitoring than higher resolution radar sensors such as SAR's because they are lower cost. Using the technique, scatterometer data can be used to extend the results of focused studies by high-resolution sensors to much larger (continental) areas. While we have limited ourselves to using $\boldsymbol{K} \boldsymbol{u}$-band SASS data in this paper, the technique can also be applied to the $C$-band ERS-1 scatterometer. A later paper will present ERS-1 results.

\section{A. Key Assumptions and Application to SASS Data}

In order to apply our resolution enhancement method to SASS data, conditions must be imposed on the data and various assumptions made. As an example of the former, in order to estimate both $Q$ and $B$ for the resolution elements, each element must be observed with a diversity of incidence angles. Our assumptions in applying this method to SASS data for this region are listed below.

1) The instrument calibration remains stable over the data acquisition interval. Limited tests of this assumption over the Amazon rain forest have indicated the calibration stability to be adequate [4].

2) Over the study regions, there is no dependence of $a$ or $B$ on the azimuth angle of the measurement, i.e., there is no azimuthal modulation of $\sigma^{\circ}$. The validity of this assumption for Amazon data is borne out by previous investigators [1], [6]. We plan further study of this issue for this and other regions in later papers.

3) The effects of surface topography are small and can be neglected. Surface slope affects the local incidence angle which, in turn, may affect the estimates of $Q$ and $B$. However, $B$, which describes the incidence angle dependence of $\sigma^{\circ}$, is relatively small (globally, $-0.08 \geq$ $\left.B \geq-0.22 \mathrm{~dB} /{ }^{\circ}\right)$. Given the small value of $B$, the relatively flat topography of the Amazon basin, and the relatively large size of the resolution elements, this assumption is reasonable.
4) The dependence of the time of day on $\sigma^{\circ}$ is small or known and correctable. Previous researchers [1], [4] have noted some time-of-day variation in $\sigma^{\circ}$ over the Amazon region. In the early morning hours, $\sigma^{\circ}$, dropped approximately $0.5 \mathrm{~dB}$, possibly due to the accumulation of dew [4]. However, only a limited number of scatterometer measurements were made during this time, with most occurring later in the day. Uncorrected diurnal variations are treated as "noise" in the imaging algorithm. This variation appears to have very little impact on our results and has, therefore, been ignored (see the discussion below). Further studies of the diurnal variability are being conducted.

5) The $Q$ and $B$ parameters over the target region remain constant over the imaging time interval. For a sufficiently short imaging time interval, this assumption is justified. However, in applying the method to SASS data, the imaging time interval must be very long (days to weeks) to obtain sufficient measurement overlap in order to achieve the desired resolution.

Kennett and $\mathrm{Li}[5]$ specifically examined the time dependency of $Q$ and $B$ at $1 \times 1^{\circ}$ resolution in their search for extended scatterometer calibration regions. During the three-month SASS mission in the late summer of 1978 , they observed time-dependent changes in the $Q$ parameter in some areas. However, over the extended Amazon basin, the only variation occurred during the first twothree weeks of the mission, and was limited to less than $1 \mathrm{~dB}$ (compare Fig. 3). We have considered imaging time intervals which include and exclude these first weeks. In this paper, the full data set was used. In a later paper, we will report on seasonal variations.

Assumptions 2), 4), and 5) may be relaxed when applying the method to suitably modified future scatterometers [7].

\section{B. Technique Validation}

The ability of the resolution enhancement algorithm to recover surface detail from the low-resolution measurements was demonstrated with simulated measurements in LHW. For actual $\sigma^{\circ}$ measurements, the lack of ground truth makes it difficult to objectively evaluate the effectiveness of the algorithm. However, we have observed a remarkable correlation between the observed $K u$-band radar backscatter characteristics $(\mathcal{Q}$ and $(B)$ and vegetation formations. This topic is explored in depth in the following section. Noting this, we have compared the backscatter from the enhanced resolution images to a map of vegetation to evaluate the capability of the radar images to discern vegetation features smaller than those resolvable in the low-resolution "binned" images. For simplicity, on the $Q$ values were used to make this comparison.

The $Q$ values from both the enhanced resolution and low-resolution "binned" images were extracted along a line from $56^{\circ} \mathrm{W} 10^{\circ} \mathrm{S}$ to $61^{\circ} \mathrm{S} 19^{\circ} \mathrm{S}$. This line was arbitrarily chosen to cross a variety of vegetation types and conditions. Fig. 4 shows the location of this line in an 


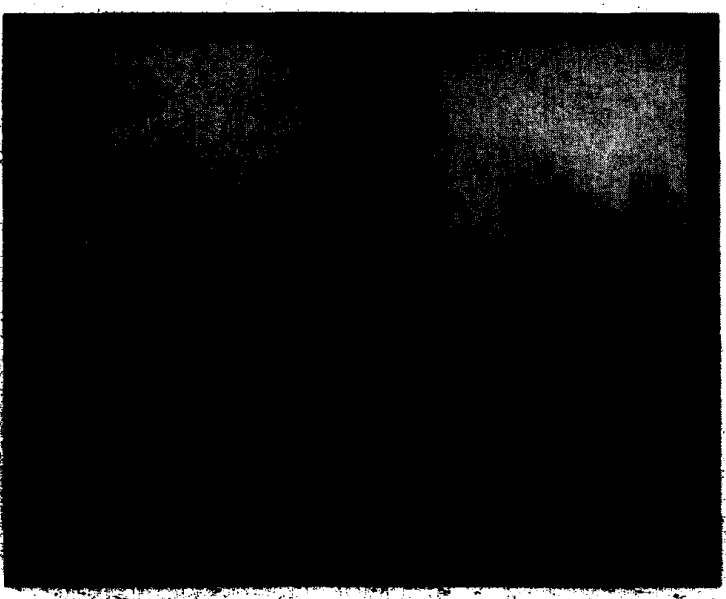

(a)

(b):

Fig. 4. An enhanced resolution (a) image and a low-resolution "binned" (b) image of $Q$ for a region in overlapping Brazil and Paraguay showing the location of a line transect used to compare the resolution of the two methods. The resolution of the low-resolution image is $0.5 \times 0.5^{\circ}$, while the pixel resolution of the enhanced resolution image is $1 / 26 \times 1 / 26^{\circ}$. The rectangular region extends from 62 to $55^{\circ} \mathrm{W}$ and from 9 to $20^{\circ} \mathrm{S}$.

expanded view of both the enhanced and low-resolution images. (An $\mathcal{Q}$ image of the full extended Amazon basin at enhanced resolution is shown in Fig. 6.) Comparison of the images in Fig. 4 reveals that the enhanced resolution image contains more detail than the low-resolution "binned"' image.

Fig. 5 shows plots of the $Q$ values from the enhanced and low-resolution images along the study line (note that $Q$ is the $\sigma^{\circ}$ value in $\mathrm{dB}$ at a $40^{\circ}$ incidence angle). Referring to this figure, we note that the $Q$ value from the enhanced image (solid line) appears to contain more detail than the $Q$ value from the low-resolution "binned" image (dashed line). Further, it is clear that the low-resolution line is not merely an averaged version of the enhanced resolution line. Using a small-scale land cover map published in 1978 by UNESCO [15] for reference, the vegetation types along this line were determined. The extent of each type along the line is indicated by the vertical dashed lines. As discussed further in a later section, the highest $Q$ response, in general, occurs for moist tropical forest with reduced values for woodlands. Grasslands typically have the lowest $a$ response.

While there is a good comparison between the map and the radar imagery, the land cover map has some limitations which must be kept in mind when using it for comparison. For example, the map contains unavoidable generalizations because the amount of detail is limited by the map scale. In addition, there is some uncertainty in the placement of vegetation boundaries due to inaccurate source material and because of the frequent existence of broad transition zones (ecotones) between vegetation classes. Classification schemes used to generate the map also demand that grouping of vegetation species be performed. Within a given class, there may be variations in

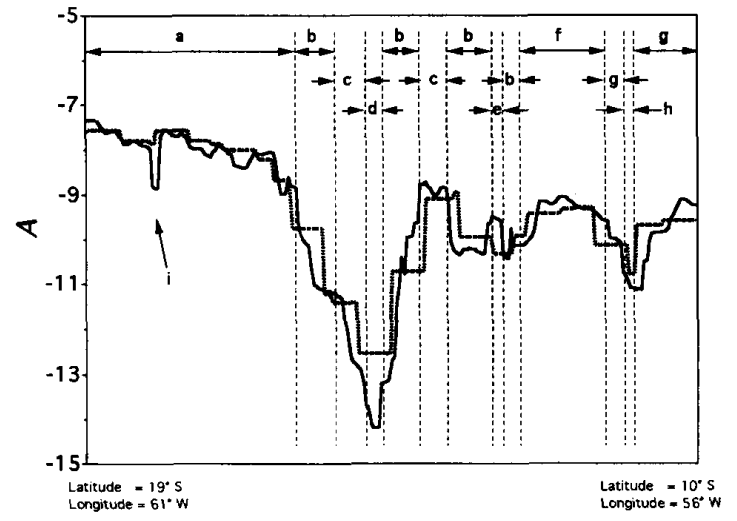

Fig. 5. $Q$ values versus distance along the line extending from $56^{\circ} \mathrm{W}, 10^{\circ} \mathrm{S}$ to $61^{\circ} \mathrm{S}, 19^{\circ} \mathrm{S}$. The solid line is the value of $Q$ from the enhanced resolution image shown in Fig. 4(a), while the dashed line is the value of $Q$ from the low-resolution "binned" image in Fig. 4(b). For an explanation of the symbols, see the text.

the relative species densities within the class. Thus, spatial variations in the radar response within each nominal vegetation class can be expected. Further, the radar response seems to be more dependent on the canopy density and vigor rather than just the physiognomic type.

In Fig. 5, type " $a$ "' corresponds to moist formations which include ombrophilous forest (which is the dominant formation along the line), and related degraded woodland and grassland mosaics. This has the highest $Q$ response. Type " $b$ " consists of variable subhumid medium-tall grasslands with woody broad-leafed evergreen woodlands. Being an ecotone, this can be expected to have a higher woodland density with a higher $Q$ response than similar formations further from type " $a$." Type " $c$ " is a subhumid degraded formation disturbed by cultivation. As discussed later, this type can be expected to exhibit a wide variation in vegetation due to various stages of clearing and regrowth. This will result in a variable $Q$ response. Type " $d$ "' is subhumid grassland mixed with shrubs. This small region has the smallest $Q$ response which is well defined in the enhanced resolution image. Type " $e$ " corresponds to subhumid medium-tall grasslands nearly devoid of shrubs. We note a close correspondence in the location of this type on the $\mathcal{Q}$ image and on the map although the observed $\mathbb{Q}$ response is somewhat higher than generally observed for this vegetation type. Type " $f$ ' is a subhumid tropical evergreen seasonal lowland forest. Type " $g$ " is edaphic tropical grassland with palms, while type " $h$ " is edaphic tropical tall grassland with palms. The dip in the enhanced resolution plot indicated by " $i$ ", corresponds to the location of a transition within type " $a$ " between a grassland and tropical forest.

Unfortunately, the precise $a$ response for each vegetation type along the study line is not known. However, we note a close correspondence with the details of the $\mathcal{Q}$ response from the enhanced resolution image and the vegetation formations along the study line. These are only weakly evident in the low-resolution image. Although the 
correspondence is not perfect, and noting the cartographic uncertainties in the map previously mentioned, we conclude with come confidence that the resolution enhancement algorithm has, indeed, provided resolution enhancement.

\section{Vertical Polarization: The amazon Basin}

Images of $Q$ and $B$ were separately generated for vertically and horizontally polarized $\sigma^{\circ}$ measurements; however, there were only $1 / 10$ as many horizontal measurements as there were vertical measurements for the study region. This occurs because the instrument was primarily operated in a dual-sided mode in which only the vertically polarized antennas on either side of the spacecraft were used. The instrument was less frequently operated in a single-side mode in which both polarizations were used. Hence, the intrinsic resolution of the horizontally polarized images is lower than the vertically polarized images, and the horizontally polarized images have "holes" due to missing coverage. For this reason, we first consider enhanced resolution images of $Q$ and $B$ generated from vertically polarized $\sigma^{\circ}$ measurements.

Fig. 6 shows an enhanced resolution $\mathbb{Q}$ estimate image generated using the SIRF algorithm and the entire threemonth SASS data set of vertically polarized $\sigma^{\circ}$ measurements. The corresponding $B$ estimate image is shown in Fig. 7. The resolution of these images is $1 / 26 \times 1 / 26^{\circ}$. For reference, Fig. 1 illustrates typical $\sigma^{\circ}$ measurement cells used to construct these images.

Perhaps the most striking feature of the $Q$ image is the obvious boundary between the light tropical rain forest in the upper half of the image and the darker savanna woodlands below. Interdigitation and transition between the woodlands and grass-shrublands are apparent in the lower right quarter of the image. The Amazon River and many of its tributaries are clearly visible against the lighter rain forest region. Within the rain forest region, there appear many small regions of woodland. The large dark region at $12^{\circ}$ south and $64^{\circ}$ west in the lower left quarter of the rain forest is an area of tropical tall grassland mixed with palms known as the Llanos de Mojos. The smaller dark areas north of the Amazon in the upper center of the image are also areas of tall grassland (very dark) mixed with scrubby trees and seasonal evergreen forest (dark gray). The broad gray area left of center in the lower portion of the image consists of woodland and thorn-forest. On the far right is dry steppe-like vegetation, mixed with agricultural areas. The highest backscatter occurs in a small region at the extreme southwest corner of the landmass shown on the image corresponding to the Salar de Atacama, a salt pan upland basin within the Atacama Desert. While not clearly evident in this reproduction, coastal urban areas also have very high backscatter.

The remarkable correlation of the $Q$ image a the vegetation map prompted us to consider using the SASS-derived images in various vegetation discrimination studies. Our results are described below. The $B$ image shows only

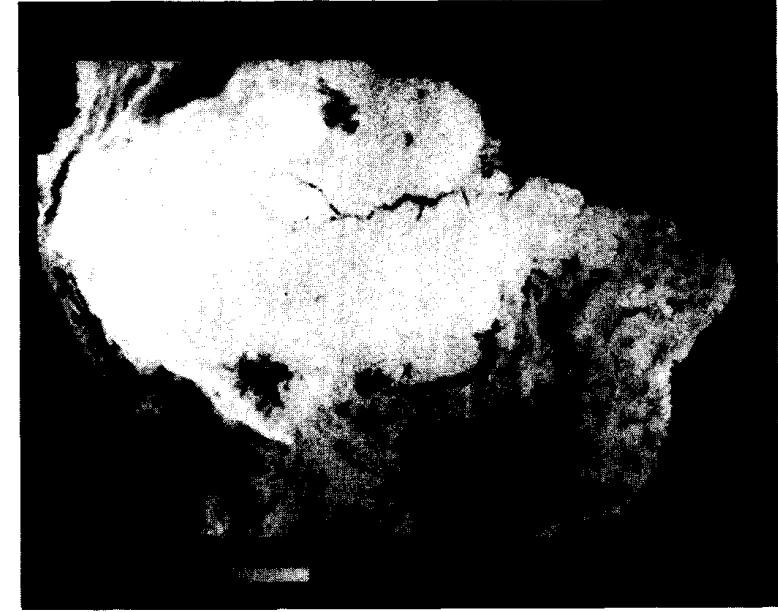

Fig. 6. Enhanced resolution $\alpha$ estimate image of the extended Amazon basin derived from three months of SASS data. This image was generated using only vertically polarized $\sigma^{\circ}$ measurements. The resolution element size is $1 / 26 \times 1 / 26^{\circ}$ (approximately $4.2 \times 4.2 \mathrm{~km}$ ). For comparison, 0.5 $\times 0.5^{\circ}$ (approximately $50 \times 50 \mathrm{~km}$ ) corresponds to the best resolution obtainable using the "binning" approach.

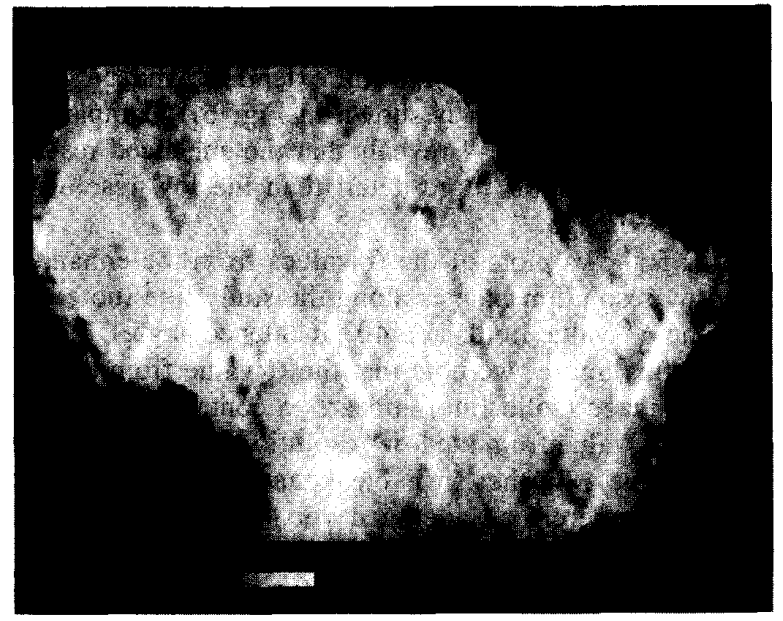

Fig. 7. Enhanced resolution $B$ estimate image corresponding to Fig. 6 .

very limited spatial detail which is generally obscured by noise artifacts; however, careful inspection of the $B$ images reveals some spatial features which correlate with the key features evident in the $Q$ images. The $B$ image provided only limited additional information in the discrimination experiments described in later sections.

We note that when seen in greater detail as depicted in the $Q$ image, the Amazon rain forest region appears to have more small-scale spatial variation than previously thought. Such inhomogeneity can contribute to the calibration uncertainty when Amazon rain forest measurements are used to calibrate the scatterometer. Use of these enhanced resolution $Q$ and $B$ images to compensate for the small heterogeneity of the rain forest region will result in improved instrument calibration accuracy. 


\section{A. Vegetation Discrimination Experiments}

As an initial evaluation of the capability of the reconstructed SASS imagery to discriminate between various vegetation types, an experiment using measurements made over the extended Amazon basin was conducted. The study area portion of the image is shown in Fig. 8. This area was selected to avoid regions where available vegetation information may be suspect and to avoid areas of high local topographic relief, e.g., the Andes.

Using the UNESCO [15] small-scale land cover map published in 1978 for reference, vegetation in the central South American study area was divided into forest, woodland, and grass-shrublands categories. The forest group consisted primarily of extremely wet rain forest types, moist seasonal forest, wet submontane forest, and related degraded forest formations. The subhumid woodland complex consisted of several vegetation communities, associated mosaics, and cultivated landscapes. The specific woodland types included $c h a c o^{2}$ and caatinga. ${ }^{3}$ The subhumid shrub-grasslands land cover class included a variety of grass-woody species mixtures, pantanal, ${ }^{4}$ and agriculture.

The statistics from the vertically polarized $Q$ image for each class and the three major groupings (forest, woodland, and shrub-grassland) are presented in Table I.

In a supervised classification experiment utilizing quadratic discriminant functions with training and withheld data sets, the vertically polarized $Q$ image data were found adequately diverse to distinguish among humid forest, woodland, and shrub-grassland with a classification accuracy rate of $88 \%$ (see Table II) [9]. Error in the classification was distributed logically between categories with similar land cover.

Sobti et al. [13] suggest that it may be more appropriate to classify terrain types predicated on "expected microwave response" instead of a priori land cover schemes. With this working hypothesis in mind and after some initial experimentation and exploratory clustering, it became apparent that between 9 and 12 unique backscatter classes existed in the data set. While somewhat greater

${ }^{2}$ Chaco-Drought deciduous lowland (and submontane) woodland. The Gran Chaco region is found in Bolivia, along the plain between the Paraguay and Parana Rivers in Paraguay, and along the Rio Paraguay in southern Brazil. This woodland is typically multicanopied and deciduous, with cactus located in drier areas. There are many climatic and edaphic variations on a local scale which are not differentiated on the map.

${ }^{3}$ Caatinga-Semi-deciduous thom scrub with succulents. It is found in northeastern Brazil in areas where the climate is subhumid to arid. It is bordered on the east by the northern variety of campos cerrados and on the east by the coastal Atlantic forest and related degraded formations. Climax caatinga formations are ligneous, drought deciduous, thickly branched, narrow leafed, and sometimes thomed. The physiognomy of caatinga is variable. In some areas, it may resemble shrubland steppe, and in other regions may be a dense scrubland with canopies reaching $10 \mathrm{~m}$. Cactus may also be found.

${ }^{4}$ Pantanal-A phytogeographical complex covering over $100000 \mathrm{~km}^{2}$ along the Rio Paraguay and its tributaries in Brazil, Bolivia, and Paraguay. the Pantanal region is primarily a humid savanna of hygrophytic grassland of which $80 \%$ is flooded during the rainy season (October-March). In areas of higher local relative relief, pantanal includes shrubs, woodland, and riparian forests along the banks of the river courses.

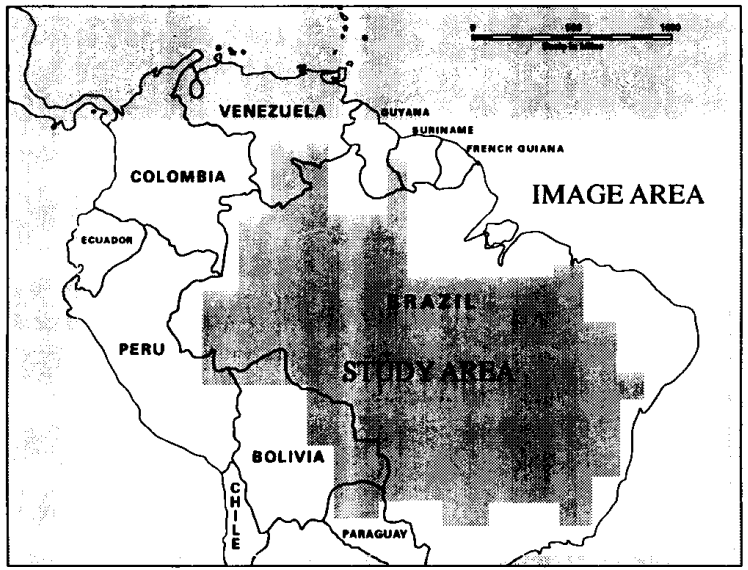

Fig. 8. Outline of the vegetation study region. The collocated vegetation indexes and image values extracted from this region were used in the vegetation discrimination experiments.

statistical divergence could be achieved using alternative divisions, a 12-cluster solution was selected due to its greater interpretability and ability to show gradations in the data. The average statistical divergence [12] between these clusters was a very high 0.96 (on a scale between 0 and 1), and the average statistical divergence between each cluster and its nearest neighboring cluster was a moderately high 0.75 . While the clusters were statistically unique, interpreting the clusters and assigning the clusters unique labels was somewhat subjective. In the discussion of the clusters below, the clusters have been ordered from highest to lowest average $\mathfrak{Q}$. Table III shows the primary formations constituting each cluster. For a formation to be considered primary, it had to either account for $10 \%$ of the pixels within the cluster or, alternatively, the cluster had to subsume at least $10 \%$ of the formation.

The first four clusters can loosely be classified as tropical forest groupings. Generally, these forests are found astride the equator in the central Amazon basin and northward into Venezuela, Guyana, and Surinam. Bounded on the east by the Pacific Ocean or a variety of coastal vegetation and agriculture, these forests stretch across the continent and extend up the eastern Andean slopes. The first (1) cluster consists of very moist forest, moist seasonal forest, wet submontane forest in northern Brazil (endings its wet season), and extremely moist forest. Cluster 2 consists of the same formations, but also includes some tropical evergreen seasonal lowland forest. Cluster 3 consists almost entirely of very moist forest and moist seasonal forest. It also should be noted that degraded forest formations make up a small fraction of these tropical forest clusters as well. Despite the introduction of some degraded woodland formation pixels, cluster 4 is primarily a forest cluster, with $81 \%$ of its pixels originating from forest formations. In summary, given the trend through the remainder of the clusters, we interpret clusters 1-4 to be tropical forest clusters with varying canopy 
TABLE I

Statistics for the 18 Groups Examined in the Supervised Discrimination ANalysis of the Vertically Polarized $\sigma^{\circ}$ DATA

\begin{tabular}{|c|c|c|c|c|}
\hline Group & Vegetation Formation & $\begin{array}{c}a \\
(\mathrm{~dB})\end{array}$ & $\begin{array}{c}\text { Q } \\
\text { Standard } \\
\text { Deviation } \\
\text { (dB) }\end{array}$ & $\begin{array}{c}\text { Pixel } \\
\text { Count }\end{array}$ \\
\hline \multirow{7}{*}{ Forest } & All forest formations & -7.62 & 0.328 & 16060 \\
\hline & Extremely moist forest & -7.19 & 0.194 & 476 \\
\hline & Moist submontane forest & -7.50 & 1.006 & 586 \\
\hline & Moist seasonal forest & -7.54 & 0.203 & 4200 \\
\hline & Degraded forest formations & -7.54 & 0.400 & 242 \\
\hline & Very moist forest & -7.67 & 0.229 & 9956 \\
\hline & Tropical evergreen seasonal forest & -7.84 & 0.589 & 600 \\
\hline \multirow{5}{*}{ Woodland } & All woodland formations & -9.33 & 0.609 & 8384 \\
\hline & Degraded woodland formations & -8.58 & 0.373 & 998 \\
\hline & Caatinga & -9.30 & 0.696 & 1866 \\
\hline & Chaco & -9.46 & 0.494 & 5184 \\
\hline & Degraded caatinga formations & -9.82 & 0.472 & 336 \\
\hline \multirow[t]{9}{*}{ Grass-shrubland } & All grass-shrubland formations & -10.39 & 1.023 & 14444 \\
\hline & Campos cerrados ( $\mathrm{N}$ formations) & -10.04 & 0.681 & 3922 \\
\hline & Campos sujos/limpos & -10.14 & 1.641 & 2030 \\
\hline & Pantanal & -10.33 & 0.938 & 2116 \\
\hline & Agriculture & -10.43 & 0.903 & 2546 \\
\hline & Degraded lowland campos cerrados & -10.65 & 0.563 & 668 \\
\hline & Grassland with palms & -10.77 & 1.126 & 642 \\
\hline & Campos cerrados (S formations) & -10.94 & 0.734 & 1836 \\
\hline & Degraded subhumid campos cerrados & -11.18 & 0.491 & 684 \\
\hline
\end{tabular}

TABLE II

Classification Accuracy Table For the Three-Group Discrimination Experiment. Overall Classification Accuracy for the Experiment WAS $84.8 \%$.

\begin{tabular}{lccc}
\hline & \multicolumn{3}{c}{ Actual Class } \\
\cline { 2 - 4 } Predicted Class & Forest & Woodland & Grass-Shrubland \\
\hline Forest & $99.2 \%$ & $10.1 \%$ & $4.8 \%$ \\
Woodland & $0.6 \%$ & $65.3 \%$ & $15.0 \%$ \\
Grass-Shrubland & $0.2 \%$ & $24.6 \%$ & $80.2 \%$ \\
\hline
\end{tabular}

densities, different canopy structures, or communities in different stages of seasonal growth or vigor.

With large mean $G$ decreases of 0.57 and $0.51 \mathrm{~dB}$, respectively, clusters 5 and 6 appear to be transition clusters between the forest and woodland groups. While $18 \%$ of the tropical evergreen seasonal lowland forest formation is included in cluster 5, woodland formations account for $62 \%$ of its membership-primarily degraded formations and caatinga. Cluster 6 is primarily wooded chaco mixed with caatinga. While these two formations are widely separated geographically, their combination is logical. First, in their typical definitions, both the caatinga and chaco can accurately be described as drought-deciduous lowland formations of woodland trees mixed with shrubs and Cactaceae. Furthermore, both formations are found in regions with nearly identical yearly precipitation characteristics, mean annual temperatures, and mean annual numbers of dry months. Specifically, the chaco is found in areas of Brazil bordering on the Rio Paraguay, and in the Chaco Province of Paraguay. These areas have a yearly precipitation between 500 and $1000 \mathrm{~mm}$, mean annual temperatures ranging between 20 and $25^{\circ} \mathrm{C}$, and six- seven dry months. The caatinga is found in areas of northeast Brazil, with yearly precipitation between 500 and $1000 \mathrm{~mm}$, mean annual temperatures between 23 and $29^{\circ} \mathrm{C}$, and between six and eight dry months [15]. Given the apparent trend in the clusters to reflect vegetation formations of increasingly sparse tree canopy cover, clusters 5 and 6 may reflect chaco with tree and shrub spacing densities similar to some areas of caatinga.

Cluster 7 is also has a mixture of caatinga and chaco, but includes $14 \%$ of the campos cerrados $(\mathrm{N})^{5}$ pixels. This northern formation of campos cerrados is found in central Brazil, and forms a zone between the Amazonian forests to the east and north and the caatinga along its western border. Physiognomy of the campos cerrados $(\mathrm{N})$ varies from a shrub savanna to woodland savanna of light to dense canopy densities. Gallery forests and areas of grassland are also common.

Cluster 8 is primarily a campos cerrados $(\mathrm{N})$ and chaco cluster, with some caatinga, and pantanal. Interestingly, $45 \%$ of the degraded caatinga formation is subsumed in this cluster, although it accounts for only $5 \%$ of the total cluster membership. Cluster 9 is also primarily a campos cerrados $(\mathbf{S})^{6}$ cluster, but contains $10 \%$ pantanal too. This southern variety of campos cerrados is distinguished from

\footnotetext{
${ }^{5}$ Campos cerrados (N)-Medium-tall grassland with several species of broad-leaved evergreen trees and shrubs. These trees and shrubs average 5 $\mathrm{m}$ in height, have thick bark, twisted branches, and partially deciduous leaves which may be hairy and leathery. Anthropogenic change, edaphic factors, and fire in the campos cerrados $(\mathrm{N})$ make the landscape extremely variable.

${ }^{6}$ Campos cerrados (S)-Medium-tall grassland with several species of broad-leaved evergreen trees and shrubs. This formation is located in Southern Brazil and north-central Paraguay. It is distinguished from campos cerrados (N) by its shorter dry season and a definite cool season. In general, possesses a denser understory than the northern campos cerrados. Primarily grassland with sedges, shorter palms are sometimes common.
} 
TABLE III

Constituent Formations for the 12 Clusters Produced from Analysis of the Vertically Polarized $Q$ Data. The $\Delta$ Values in the Mean $Q$ Column Represent the Increase in Mean $Q$ from the Preceding Cluster Charted.

\begin{tabular}{|c|c|c|c|c|c|c|}
\hline $\begin{array}{l}\text { Cluster } \\
\text { Index }\end{array}$ & $\underset{\text { Mean }}{a}$ & $\begin{array}{c}Q \\
\text { St. } \\
\text { Den. }\end{array}$ & $\begin{array}{l}\text { Pixel } \\
\text { Count }\end{array}$ & Primary Formations & $\begin{array}{l}\text { Percentage of } \\
\text { Cluster }\end{array}$ & $\begin{array}{c}\text { Percentage of } \\
\text { Formation }\end{array}$ \\
\hline \multirow[t]{5}{*}{1} & -7.17 & 0.142 & 132 & Very moist forest & 32 & 8 \\
\hline & & & & Moist seasonal forest & 24 & 15 \\
\hline & & & & Wet submontane forest & 14 & 63 \\
\hline & & & & Extremely moist forest & 13 & 77 \\
\hline & & & & Degraded forest formations & 3 & 36 \\
\hline \multirow[t]{6}{*}{2} & -7.49 & 0.080 & 2927 & Very moist forest & 52 & 30 \\
\hline & & & & Moist seasonal forest & 39 & 55 \\
\hline & $\Delta=0.32$ & & & Tropical evergreen seasonal lowland forest & 3 & 28 \\
\hline & & & & Extremely moist forest & 2 & 26 \\
\hline & & & & Wet submontane forest & 2 & 18 \\
\hline & & & & Degraded forest formations & 1 & 27 \\
\hline \multirow[t]{3}{*}{3} & -7.75 & 0.074 & 2871 & Very moist forest & 78 & 45 \\
\hline & & & & Moist seasonal forest & 17 & 24 \\
\hline & $\Delta=0.26$ & & & Degraded forest formations & 1 & 26 \\
\hline \multirow[t]{4}{*}{4} & -8.01 & 0.110 & 1121 & Very moist forest & 67 & 15 \\
\hline & & & & Moist seasonal forest & 11 & 6 \\
\hline & $\Delta=0.26$ & & & Degraded woodland formations & 10 & 23 \\
\hline & & & & Tropical evergreen seasonal lowland forest & 3 & 12 \\
\hline \multirow[t]{3}{*}{5} & -8.58 & 0.153 & 746 & Degraded woodland formations & 38 & 57 \\
\hline & & & & Caatinga & 24 & 19 \\
\hline & $\Delta=0.57$ & & & Tropical evergreen seasonal lowland forest & 7 & 18 \\
\hline \multirow[t]{3}{*}{6} & -9.09 & 0.102 & 1736 & Chaco & 58 & 39 \\
\hline & & & & Caatinga & 11 & 20 \\
\hline & $\Delta=0.51$ & & & Agriculture & 7 & 10 \\
\hline \multirow[t]{4}{*}{7} & -9.40 & 0.094 & 1779 & Chaco & 53 & 36 \\
\hline & & & & Campos cerrados $(\mathrm{N})$ & 14 & 13 \\
\hline & $\Delta=0.31$ & & & Caatinga & 12 & 23 \\
\hline & & & & Agriculture & 10 & 14 \\
\hline \multirow[t]{5}{*}{8} & -9.76 & 0.106 & 1669 & Campos cerrados $(\mathrm{N})$ & 39 & 33 \\
\hline & & & & Chaco & 21 & 13 \\
\hline & $\Delta=0.36$ & & & Caatinga & 10 & 18 \\
\hline & & & & Pantanal & 9 & 15 \\
\hline & & & & Degraded caatinga formations & 5 & 45 \\
\hline \multirow[t]{3}{*}{9} & -10.15 & 0.124 & 1271 & Campos cerrados $(\mathrm{N})$ & 38 & 25 \\
\hline & & & & Campos cerrados (S) & 12 & 16 \\
\hline & $\Delta=0.39$ & & & Pantanal & 11 & 14 \\
\hline \multirow[t]{6}{*}{10} & -10.62 & 0.159 & 1206 & Campos cerrados $(\mathrm{N})$ & 21 & 13 \\
\hline & & & & Campos cerrados (S) & 15 & 20 \\
\hline & $\Delta=0.47$ & & & Pantanal & 15 & 17 \\
\hline & & & & Campos sujos/limpos & 10 & 12 \\
\hline & & & & Agriculture & 10 & 9 \\
\hline & & & & Grassland with palms & 7 & 25 \\
\hline \multirow[t]{6}{*}{11} & -11.19 & 0.190 & 2121 & Agriculture & 30 & 50 \\
\hline & & & & Campos cerrados $(\mathrm{S})$ & 18 & 42 \\
\hline & $\Delta=0.51$ & & & Pantanal & 12 & 25 \\
\hline & & & & Degraded subhumid campos cerrados & 11 & 68 \\
\hline & & & & Campos sujos/limpos & 7 & 16 \\
\hline & & & & Grassland with palms & 5 & 34 \\
\hline \multirow[t]{5}{*}{12} & -12.08 & 0.383 & 668 & Campos sujos/limpos & 36 & 24 \\
\hline & & & & Campos cerrados $(\mathrm{S})$ & 19 & 14 \\
\hline & $\Delta=0.89$ & & & Campos cerrados $(\mathrm{N})$ & 13 & 4 \\
\hline & & & & Pantanal & 12 & 8 \\
\hline & & & & Grassland with palms & 9 & 19 \\
\hline
\end{tabular}

campos cerrados $(\mathrm{N})$ by its shorter dry season and definite cool season. The remaining $29 \%$ of the cluster pixels is accounted for by other members of the woodland and shrub-grassland formations. While cluster 10 is also a campos cerrados (N\&S) cluster, a significant number of grassland formations account for a large percentage of the pixels, including pantanal, campos sujos, ${ }^{7}$ campos lim-

${ }^{7}$ Campos sujos-"Dirty Grassland." A prairie grassland with scattered shrubs. Within the study area of this paper, they are located along the upper Rio Branco in northern Brazil. $p o s,{ }^{8}$ and grassland with palms. Given the moderate decrease in backscatter from the previous cluster $(0.47 \mathrm{~dB})$ and the entry of grassland constituents into the cluster, cluster 10 represents a transition between woodlandshrubland clusters to shrubland-grassland clusters.

Cluster 11 has a mean $Q$ of $0.57 \mathrm{~dB}$ less than cluster 10 , and consists primarily of agriculture and grasslands.

${ }^{8}$ Campos limpos - Tall prairie grassland nearly devoid of shrubs and trees. Within the study area, these areas are mixed with campos sujos in northern Brazil. 
It also include $42 \%$ of the campos cerrados (S) pixels, $68 \%$ of the degraded subhumid campos cerrados formation, and $34 \%$ of the grassland with palms. Cluster 12 has an average $Q$ of nearly a decibel lower than cluster 11 , and consists mostly of campos sujos/limpos. Almost $20 \%$ of the grassland with palms formation is subsumed in this cluster, with small percentages of campos cerrados (N\&S).

In attempting to assess the meaning of each cluster, the limitations of using the UNESCO map for ground truth, will all its cartographic generalization and classification became apparent-it does not contain sufficient areal detail within the mapped formations to account for the observed detail captured in the clustering analysis. Based on 1) the pattern exhibited in the clustering, 2) the nominal cluster constituents, 3) the general formation descriptions, and 4) the consistency of the results through the cluster sequence, it seems that the $Q$ coefficients are expressions of a large-scale physiognomic characteristic typical of the formations rather than the species composition of each formation. For an individual pixel, we hypothesize that this characteristic is canopy density/cover integrated over the $\approx 16 \mathrm{~km}^{2}$ area spanned by a single pixel. This implies that the relative amounts of bare ground, grass, shrubbery, and trees that very between (and within) formations also will be reflected in the backscatter coefficients. The phenophase (i.e., seasonal growth stage) with its attendant differences in vigor, changing canopy structures, and canopy moisture content will also influence the backscatter values. However, given the information from the map, this hypothesis cannot be definitively tested. Further research to investigate these hypotheses continues.

\section{Vi. Horizontal Versus Vertical Polarization}

While SASS generally operated in vertical polarization modes, it also made a limited number of horizontally polarized $\sigma^{\circ}$ measurements. Over the study region, these were made primarily during two one-week periods in the first month of the mission. Coupled with the criss-cross coverage pattern (refer to [7]), horizontally polarized measurements were not made at all over several diamondshaped regions in our study area. In addition, because there were fewer horizontally polarized measurements than vertically polarized measurements, the intrinsic resolution of any reconstructed $Q$ and $B$ images from the horizontally polarized $\sigma^{\circ}$ measurements would much coarser than the vertically polarized $Q$ and $B$ images.

While the paucity of the horizontally polarized data limits our ability to draw firm conclusions, we have found the addition of the horizontally polarized measurements increases our ability to distinguish between some varieties of tropical vegetation. Our results are presented below. In the following discussion, subscripts are used to distinguish $Q$ and $B$ values derived from vertically polarized and horizontally polarized $\sigma^{\circ}$ measurements.

In Section IV-A, we presented the results of a super- vised discrimination experiment using only vertically polarized $Q\left(Q_{v}\right)$ image data. In this section, we consider how these discrimination results are affected by including the vertically polarized $B\left(B_{v}\right)$ image and the horizontally polarized $Q$ and $B$ images $\left(Q_{h}\right.$ and $\left.B_{h}\right)$. Three of the 18 vegetation classes used in Section IV-A were excluded from this experiment because of the lack of coverage by horizontally polarized SASS measurements. The statistics for 15 remaining vegetation classes are shown in Table IV.

As evident in Table IV, the $Q_{h}$ coefficients were, as a rule, lower than the corresponding $Q_{v}$ coefficients. It is also apparent the smallest differences between the average $Q_{h}$ and $Q_{v}$ values exist between members of the forest group $(\Delta \approx 0.0)$, and the difference increases slightly in the woodland group $(\Delta \approx 0.05)$ and dramatically in the grass-shrubland group ( $\Delta \approx-0.73$ ). Formations having the greatest proportion of grassland, such as campos sujos/limpos $(\Delta \approx-0.97)$, pantanal $(\Delta \approx-1.09)$, and grassland with palms $(\Delta \approx-0.85)$ display the greatest differences between $Q_{h}$ and $Q_{v}$ values. The standard deviations shown in Table $V$ also indicate that the variability in the $Q$ backscatter coefficients was smallest in the forest group, somewhat larger in the woodland group, and greatest within the grass-shrubland group. With the exception of the woodland $B$ standard deviation values, the vertical coefficients displayed less variation than the horizontal coefficients.

When compared on a pixel-by-pixel basis, there is a significant linear correlation between the $Q_{v}$ and $Q_{h}$ coefficients for several of the classes. An interesting pattern is evident for the forest, woodland, and grass-shrubland groups. There is only slight correlation $(r=0.31)$ among corresponding $\mathbb{Q}_{v}$ and $\boldsymbol{Q}_{h}$ coefficients for the forest group, with some members of the group (e.g., very moist forest) showing almost no correlation. For these members, this indicates that the difference $(\Delta)$ between the $Q_{v}$ and $Q_{h}$ values for individual pixels is primarily due to randomness or noise rather than the measurement polarity. The linear correlation between pixels increases through the woodland $(r=0.64)$ and grass-shrubland $(r=0.77)$ vegetation groups. For these groups, this indicates that the polarity of the measurements is a factor in the value of the $Q$ coefficients. It is interesting to note that the greatest polarization dependence (as shown by $r$ ) is within the agriculture class $(r=0.83$ ).

In order to explore the effects of polarization on actual discrimination results, the supervised discrimination experiment described in Section IV-A (but with only the 15 vegetation classes) was conducted using all possible combinations (there are 15) of the $\mathbb{Q}_{v}, B_{v}, Q_{h}$, and $\AA_{h}$ image data. As in the previous experiment, the 15 vegetation categories were subdivided into forest, woodland, and grass-shrubland before conducting the quadratic discriminant analyses.

The results for the 15 classification experiments are summarized in Table VI. This table shows the coefficient variables used in each classification experiment tabled 
TABLE IV

Summary $\mathbb{Q}_{i}, \mathbb{B}_{i}, \mathbb{Q}_{h}$, And $\mathbb{B}_{h}$ Coefficient Information for the 15 Vegetation Classes Used in Contrasting the Discriminating Ability of rhe Horizontally and Vertically Polarized Data

\begin{tabular}{|c|c|c|c|c|c|c|c|}
\hline Group & Vegetation Formation & $\begin{array}{c}Q_{r} \\
\text { (dB) }\end{array}$ & $\begin{array}{c}Q_{h} \\
(\mathrm{~dB})\end{array}$ & $\begin{array}{c}Q_{1}-Q_{h} \\
\Delta\end{array}$ & $\begin{array}{c}\mathbb{Q}_{r}-\mathbb{Q}_{h} \\
\text { Pearson's } \\
r\end{array}$ & $\begin{array}{c}B_{\prime^{\prime}} \\
\left(\mathrm{d} B /{ }^{\circ}\right)\end{array}$ & $\begin{array}{c}\boldsymbol{B}_{h} \\
\left(\mathrm{~dB} /{ }^{\circ}\right)\end{array}$ \\
\hline \multirow[t]{6}{*}{ Forest } & All forest formations & -7.67 & -7.67 & 0.00 & 0.31 & -0.120 & -0.123 \\
\hline & Moist seasonal forest & -7.53 & -7.49 & -0.04 & 0.15 & -0.122 & -0.120 \\
\hline & Degraded forest formations & -7.62 & -7.18 & -0.08 & 0.57 & -0.125 & -0.128 \\
\hline & Very moist forest & -7.72 & -7.80 & +0.08 & 0.05 & -0.118 & -0.124 \\
\hline & Tropical evergreen seasonal forest & -8.02 & -7.78 & -0.24 & 0.62 & -0.123 & -0.123 \\
\hline & Wet submontane forest & -8.16 & -7.91 & -0.25 & 0.69 & -0.123 & -0.129 \\
\hline \multirow[t]{4}{*}{ Woodland } & All woodland formations & -9.07 & -9.02 & -0.05 & 0.64 & -0.111 & -0.122 \\
\hline & Degraded woodland formations & -8.59 & -8.22 & -0.37 & 0.52 & -0.124 & -0.125 \\
\hline & Chaco & -9.28 & -9.42 & +0.14 & 0.21 & -0.103 & -0.119 \\
\hline & Caatinga & -9.30 & -9.00 & -0.30 & 0.23 & -0.119 & -0.129 \\
\hline \multirow[t]{8}{*}{ Grass-Shrubland } & All grass-shrubland formations & -10.39 & -9.66 & -0.73 & 0.77 & -0.124 & -0.126 \\
\hline & Campos sujos/limpos & -9.86 & -8.89 & -0.97 & 0.75 & -0.128 & -0.133 \\
\hline & Campos cerrados & -10.18 & -9.61 & -0.57 & 0.80 & -0.120 & -0.119 \\
\hline & Pantanal & -10.31 & -9.22 & -1.09 & 0.74 & -0.122 & -0.127 \\
\hline & Grassland with palms & -10.68 & -9.83 & -0.85 & 0.74 & -0.126 & -0.128 \\
\hline & Degraded lowland campos cerrados & -10.69 & -10.30 & -0.39 & 0.39 & -0.119 & -0.125 \\
\hline & Agriculture & -10.69 & -10.25 & -0.44 & 0.83 & -0.125 & -0.123 \\
\hline & Degraded subhumid campos cerrados & -11.45 & -10.89 & -0.56 & 0.55 & -0.131 & -0.128 \\
\hline
\end{tabular}

TABLE V

Standard Deviation Values for the Three Main Vegetation Groups. With the Single Exception of the Woodland $B$, Value, the Variability Within the Horizontally Polarized CoefFicients Was Higher than the Variability in the Vertically Polarized COEFFICIENTS.

\begin{tabular}{lcccc}
\hline & $\begin{array}{c}\mathfrak{Q}_{r^{\prime}} \\
\text { Standard } \\
\text { Deviation } \\
(\mathrm{dB})\end{array}$ & $\begin{array}{c}\boldsymbol{Q}_{h} \\
\text { Standard } \\
\text { Deviation } \\
(\mathrm{dB})\end{array}$ & $\begin{array}{c}\mathbb{B}_{c^{\prime}} \\
\text { Standard } \\
\text { Deviation } \\
\left(\mathrm{dB} /{ }^{\circ}\right)\end{array}$ & $\begin{array}{c}\boldsymbol{B}_{h} \\
\text { Standard } \\
\text { Deviation } \\
\left(\mathrm{dB} /{ }^{\circ}\right)\end{array}$ \\
\hline Forest & 0.330 & 0.563 & 0.0035 & 0.0049 \\
Woodland & 0.470 & 0.737 & 0.0109 & 0.0048 \\
Grass-Shrubland & 1.108 & 1.271 & 0.0046 & 0.0056 \\
\hline
\end{tabular}

TABLE VI

The Results of THE 15 Group Classification Experiments Contrasting the Discriminating ABility of the Horizontally and Vertically Polarized Data. The Table Entries are Sorted by ASCENDING ACCURACY OF ClaSSIFICATION.

\begin{tabular}{|c|c|c|c|c|c|}
\hline $\begin{array}{c}Q_{v^{\prime}} \\
\text { Included }\end{array}$ & $\begin{array}{c}Q_{h} \\
\text { Included }\end{array}$ & $\begin{array}{c}\beta_{z} \\
\text { Included }\end{array}$ & $\begin{array}{c}\beta_{h} \\
\text { Included }\end{array}$ & Kappa & Percentage \\
\hline & & & Yes & 0.140 & 51.6 \\
\hline & & Yes & & 0.410 & 65.0 \\
\hline & & Yes & Yes & 0.498 & 70.3 \\
\hline & Yes & & & 0.565 & 73.7 \\
\hline & Yes & & Yes & 0.624 & 77.1 \\
\hline & Yes & Yes & & 0.755 & 85.5 \\
\hline & Yes & Yes & Yes & 0.778 & 86.7 \\
\hline Yes & & & & 0.789 & 86.8 \\
\hline Yes & & & Yes & 0.803 & 87.7 \\
\hline Yes & Yes & & & 0.815 & 88.6 \\
\hline Yes & Yes & & Yes & 0.830 & 89.5 \\
\hline Yes & & Yes & & 0.891 & 93.4 \\
\hline Yes & & Yes & Yes & 0.905 & 94.2 \\
\hline Yes & Yes & Yes & & 0.906 & 94.3 \\
\hline Yes & Yes & Yes & Yes & 0.914 & 94.7 \\
\hline
\end{tabular}

against the simple percentage and Cohen's kappa accuracy figures resulting from the classification. Kappa is an accuracy metric which, unlike a simple percentage, ac- counts for the classification accuracy which could be expected by the operation of random chance alone. (The reader unfamiliar with Cohen's kappa may wish to review [11] for a discussion of its calculation and merits.) In comparing classifications, kappa is a more useful measure of discriminating power than is percent, particularly in experiments producing low accuracies and/or involving very few classes. A kappa of 0 indicates that there is no discrimination between the classes, while a kappa of 1.0 indicates that errorless discrimination may be achieved.

From the table, a number of conclusions can be drawn. First, discrimination using coefficients derived from the vertically polarized data is always superior to discrimination predicated on their horizontally polarized counterparts. Second, experiments utilizing a single $Q$ theme (i.e., $Q_{v}$ or $Q_{h}$ ) exhibit significantly enhanced discrimination capability when the corresponding $B$ coefficient is added. The enhancement, however, is more noticeable in the vertical polarization case. Finally, if $Q_{v}$ and $\beta_{v}$ data are utilized, a small but significant amount of discrimination ability is gained in adding horizontally polarized coefficient data.

Based on the results summarized in Tables IV-VI, it appears that there is significant polarization dependence in $14.6 \mathrm{GHz}$ backscatter for tropical woodlands, grasslands, and some tropical forest formations. It also appears that the difference between vertical and horizontal $\sigma^{\circ}$ is generally small in tropical forest formations, but increases in tropical woodland and grass-shrubland formations. This implies that improved vegetation discrimination between tropical forest and other vegetation groups can be achieved when both vertically polarized and horizontally polarized measurements are available. Finally, despite the variance in the $B$ coefficient data, the $B$ coefficient data do support a small amount of discrimination (particularly $\AA_{v}$ ). 
Despite the results from the classification comparisons, the reader should not assume that vertically polarized 14.6 $\mathrm{GHz} \sigma^{\circ}$ measurements are superior to horizontally polarized $\sigma^{\circ}$ measurements for discriminating between subtropical vegetation. It must be remembered that the reconstructed $Q_{h}$ and $Q_{h}$ images used in these experiments are based on many fewer $\sigma^{\circ}$ measurements than the reconstructed $Q_{v}$ and $\mathrm{B}_{v}$ images. Since all four images were reconstructed to the same resolution, there is more noise in the $Q_{h}$ and $B_{h}$ images than in their vertically polarized counterparts (see Table $\mathrm{V}$ and the resolution versus noise tradeoff in the companion paper [7]). Hence, an alternative interpretation of the decreased classification accuracy of the horizontally polarized measurements may simply be that there is less noise in the $Q_{v}$ and $\mathbb{B}_{v}$ estimates and, by extension, better class discrimination.

\section{ConClusion}

Traditionally, spaceborne scatterometers have been low-resolution radar instruments designed to measure winds over the ocean. Because of their low resolution, the scatterometer measurements made over land have been used primarily to calibrate the instrument. However, studies of scatterometer measurements over land have hinted at the sensitivity of the scatterometer measurements to vegetation and ice coverage.

In a separate paper [7], we described a method for obtaining enhanced resolution radar images from low-resolution scatterometer measurements. To validate our resolution enhancement scatterometer imaging technique, we have processed SASS data into radar images of the Amazon basin. We used these data to study and classify the observed vegetation, and have found a remarkable correlation between the radar images and the vegetation type leading to impressive discrimination capability. Our results suggest that medium-scale, enhanced resolution scatterometer data can be useful in vegetation studies (see also [9]). We postulate that the enhanced data will be useful in a variety of other geophysical studies, e.g., ice [8].

Our resolution enhancement technique can be used to augment the data from existing and planned scatterometers as a "technique of opportunity," leading to more effective use of the instruments with little associated cost. In particular, applying the technique to SASS data provides a unique historical data set for studies in global change.

The wide-area, frequent coverage of the enhanced scatterometer data is particularily well suited for large-scale monitoring. The enhanced resolution scatterometer data can be used to extend the results of focused studies made in conjunction with high-resolution sensors to much larger (continental) areas. The high absolute accuracy of the scatterometer measurements and their wide incidence angle diversity can be significant advantage for geophysical modeling. While we have limited ourselves to SASS data in this paper, the technique can also be applied to the $C$ band ERS-1 scatterometer as well as other sensors.

\section{ACKNOWLEDGMENT}

We wish to acknowledge D. Adamec and R. Thomas. The SASS SDR data were obtained from the NASA Ocean Data System at the Jet Propulsion Laboratory/California Institute of Technology.

\section{REFERENCES}

[1] I. J. Birrer, E. M. Bracalente, G. J. Dome, J. Sweet, and G. Berthold, " $\sigma$ " signature of the Amazon rainforest obtained from the seasat scatterometer," IEEE Trans. Geosci. Remote Sensing, vol. GE-20, no. 1, pp. 11-17, 1982.

[2] D. H. Boggs, "Seasat algorithm development facility scatterometer sensor algorithm specifications," Seasat Doc. 622-231, Jet Propulsion Lab., Pasadena, CA, May 1981.

[3] E. Bracalente, D. Boggs, W. Grantham, and J. Sweet, "The SASS scattering coefficient $\left(\sigma^{\circ}\right)$ algorithm," IEEE J. Oceanic Eng., vol. OE-5, pp. 145-154, Apr. 1980.

[4] E. Bracalente and J. Sweet, "Analysis of normalized radar cross section $\left(\sigma_{\mathrm{o}}\right)$ signature of Amazon rain forest using Seasat scatterometer data," NASA Tech. Memo. 85779, NASA NTIS, 1984.

[5] R. G. Kennett and F. K. Li, "Seasat over-land scatterometer data, Part I: Global overview of the $K u$-band backscatter coefficients," IEEE Trans. Geosci. Remote Sensing, vol. 27, pp. 592-605, Sept. 1989.

[6] —, "Seasat over-land scatterometer data, Part II: Selection of extended area land-target sites for the calibration of spaceborne scatterometers," IEEE Trans. Geosci. Remote Sensing, vol. 27, pp. 779788, Nov. 1989.

[7] D. G. Long, P. J. Hardin, and P. T. Whiting, "Resolution enhancement of spaceborne scatterometer data," IEEE Trans. Geosci. Remote Sensing, vol. 31, no. 3, pp. 700-715, 1993.

[8] D. G. Long and M. Drinkwater, "Greenland observed at enhanced resolution by the Seasat-A scatterometer," in press J. Geophys. Res., 1994.

[9] P. J. Hardin and D. G. Long, "Discriminating between subtropical vegetation formations using reconstructed high-resolution Seasat-A scatterometer data,"' in press Photogramm. Eng. Remote Sensing, 1994.

[10] J. W. Johnson, L. A. Williams, Jr., E. M. Bracalente, F. B. Beck, and W. L. Grantham, "Seasat-A satellite scatterometer instrument evaluation," IEEE J. Oceanic Eng., vol. OE-5, pp. 138-144, Apr. 1980.

[11] G. H. Rosenfield and K. Fitzpatrick-Lins, "A coefficient of agreement as a measure of thematic classification accuracy," Photogramm. Eng. Remote Sensing, vol. 52, pp. 223-227, 1986.

[12] A. Singh; "Some clarifications about the pairwise divergence measure in remote sensing," Int. J. Remote Sensing, vol. 5, pp. 623627,1984

[13] A. Sobti, R. K. Moore, and F. T. Ulaby, "Backscatter response at $13.9 \mathrm{GHz}$ for major terrain types as seen from orbit," Tech. Rep. 243-4, NASA Lyndon B. Johnson Space Cen., Houston, TX, Aug $15,1975$.

[14] R. H. Stewart, "Seasat success statement," Jet Propulsion Lab., Publ. D-2841, Pasadena, CA, Apr. 11, 1985

[15] UNESCO, Vegetation Map of South America $(1: 5,000,000$, two sheets) and Vegetation Map of South America Explanatory Notes, United Nations Education, Scientific and Cultural Organization, Paris, France, 1980 and 1981.

David G. Long, photograph and biography not available at time of publication.

Perry J. Hardin, photograph and biography not available at time of publication. 